\title{
MOTIVAÇÃO COMO FERRAMENTA PARA AUMENTO DA PRODUTIVIDADE EM EMPRESAS FAMILIARES
}

\author{
MOTIVATION AS A TOOL FOR INCREASING \\ PRODUCTIVITY IN FAMILY BUSINESS
}

Recebido: 12/08/2015 - Aprovado: 23/10/2015 - Publicado: 29/12/2015 Processo de Avaliação: Double Blind Review

\author{
Mauro Laruccia ${ }^{1}$ \\ Pós doutorado em Comunicação \\ Doutor em comunicação e semiótica \\ Docente da UNISO - Universidade de Sorocaba \\ Docente da PUC-SP - Pontifícia Universidade Católica de São Paulo \\ mauro.laruccia@gmail.com
}

\author{
Ana Maria Jansen Matias \\ Mestre em Comunicação e Educação \\ Docente das Faculdades Integradas Campos Salles \\ Docente da Faculdade Carlos Drummond de Andrade \\ anajansenmatias@ hotmail.com. \\ Bruno da Silva Passos \\ Graduado em Administração \\ Faculdades Integradas Campos Salles
}

\begin{abstract}
RESUMO: Esta pesquisa relata as definições de empresa familiar, suas características, seus pontos fortes, pontos a desenvolver e como estas variáveis podem ou não ocorrer e interferir no ambiente organizacional das empresas. Discorre sobre o que desperta a motivação em um colaborador e as teorias motivacionais. A liderança, as formas de se liderar, a importância de um líder para motivar os colaboradores. Traz o estudo de caso de uma empresa, localizada nos bairros da Lapa e Vila Olímpia, em São Paulo. Apresenta a estrutura e as diretrizes da empresa quanto aos seus pontos fortes e fracos a partir da aplicação de um questionário sobre a motivação, aplicado aos funcionários e demonstrado em gráficos que analisados permitem que se tracem sugestões de melhoria por meio de teorias justificadas cientificamente.
\end{abstract}

PALAVRAS CHAVE: Gestão de Empresa Familiar; Motivação e Liderança Organizacional; Otimização da Produtividade.

\footnotetext{
1 Autor para correspondência: Pontifícia Universidade Católica de São Paulo, Rua Monte Alegre, 984, Perdizes, São Paulo, SP, Brasil - CEP 05014-901.
} 
ABSTRACT: This survey reports the definitions of family business, its technical features, their strengths, and points to develop and which manner these variables may or may not occur and interfere in the organizational environment of enterprises. Discourse the awakening motivation in collaborative in addition to motivational theories. The leadership, the ways to lead, the pin point of a leader to motivate staff team. It brings the case study in a company, located in the neighborhoods of Lapa and Vila Olimpia, Sao Paulo. Announces the structure and company guidelines, moreover, their strengths and weaknesses from the application of a questionnaire on motivation applied to employees and presented in graphs that analyzed, allowing to trace suggestions for improvement through scientifically justified theories.

KEYWORDS: Family Business Management; Motivation and Organizational Leadership; Optimizing Productivity.

\section{INTRODUÇÃO}

No atual cenário organizacional, as empresas estão descobrindo a importância do bem estar social, emocional e profissional de seus colaboradores, e o quanto esses atributos são importantes para obter a capacidade produtiva máxima de cada indivíduo. Apesar de sua complexidade, as organizações se interessam cada vez mais pela mente humana, e estão provando que as mais antigas teorias motivacionais fazem sentido, uma vez que, quanto mais se interessam pelo bem estar do colaborador, mais obtêm resultados. A palavra produtividade está totalmente relacionada com bem estar. As empresas estão percebendo a importância desses dois conceitos e se adaptam ao mercado de acordo com o entendimento desse novo mundo. As empresas familiares, assim como as grandes organizações, têm maior responsabilidade no que se refere à motivação dos colaboradores. Apesar de serem estruturalmente menores do que as grandes organizações, essas empresas têm papel fundamental na qualidade de vida (física e emocional) dos seus empregados.

O objetivo geral da pesquisa é apurar o grau de motivação dos colaboradores de uma empresa familiar, analisando o quanto este fato é realmente importante e se isso interfere diretamente nas atividades exercidas por eles. Os objetivos específicos são: Diagnosticar possíveis problemas na empresa. Apontar as possíveis causas e relacionamento com o trabalho desenvolvido. Averiguar a relação das necessidades individuais de cada indivíduo com a motivação. Fornecer as soluções adequadas que visariam melhorar a motivação e desenvolvimento dos colaboradores. Obter resultado positivo, quanto às soluções apontadas pela análise e aplicabilidade deste trabalho. 
Em um mercado cada vez mais competitivo cabe às empresas se destacarem como motivadoras de seus colaboradores. Saber lidar com diferentes situações, problemas que nem sempre envolvem o ambiente de trabalho e conflitos, são alguns exemplos de como os gestores devem saber tomar atitudes quando colocados frente a essas situações. Motivação no ambiente corporativo nem sempre esta ligado apenas às recompensas e gratificações, porém estes são fundamentais para o trabalhador, ainda mais em se tratando da analise de empresas familiares, em constante surgimento e crescimento no Brasil.

Saber identificar os problemas que afligem as empresas familiares é um ponto focal e importante para o desenvolvimento deste artigo; questão essa, que se pretende responder através das pesquisas bibliográficas, aplicando as diferentes teorias escolhidas e pesquisa de campo, que visa entender a visão dos principais envolvidos; a empresa e seus colaboradores.

De fato, é cada vez mais desafiante entender o que motiva ou desmotiva um indivíduo. Por isso, se faz necessário fazer uma pesquisa bibliografia diversificada e rica, assim, compilando os dados levantados, analisando os fatos e concluindo uma possível hipótese que aponte o que poderia estar afetando a motivação e o desenvolvimento dos colaboradores.

\section{EMPRESA FAMILIAR}

Segundo Macedo (2009), empresas familiares são empresas em que uma ou mais pessoas de uma mesma família exercem controle administrativo sobre o negocio, atualmente cerca de $90 \%$ das empresas brasileiras são familiares. Geralmente essas empresas são presididas pelo chefe da família ou pelas gerações seguintes às do fundador, existem vários tipos de empresa familiares, cada qual com suas particularidades e especificidades que as diferirão das demais.

O fundador de uma empresa familiar tem senso empreendedor. "Um empreendedor audaz, detentor de uma ideia e certa tecnologia, monta o seu negócio em geral com o auxílio da própria família e alguns poucos empregados" (GRZYBOVSKI e TEDESCO, 1998, pg. 44). As empresas familiares são foco de alguns estudos, que na maioria das vezes abordam aspectos que cercam as empresas e passam por temas como, 
o perfil dos sócios e dos colaboradores, gestão, criação, sucessão, falência e outros que cercam o ambiente organizacional familiar. $\mathrm{O}$ assunto tem sido vinculado na mídia como meio de oportunidade lucrativa.

Quando se fala em gestão de empresas familiares, há varias incógnitas, pois por ser dono do seu próprio negocio, esse administrador pode dirigir sua empresa de maneira diferente dos métodos mais comuns do mercado, fazendo com que ela se diferencie (no mercado) abrangendo um novo público e aumentando sua popularidade. Outro grande ponto das empresas familiares é a competitividade em torno do ramo que juntamente com a gestão diferenciada pode acarretar no sucesso dessas organizações. Pode-se somar uma grande fatia a esse sucesso, o modo como o Administrador trabalha o capital intelectual e atende não somente suas expectativas, mas também as necessidades de seus colaboradores. É fato que um negócio onde todos os colaboradores estão motivados, tende a ter maior sucesso. A gestão de pessoas e implementação de novas práticas, faz com que não somente a empresa prospere, mas também com que os seus empregados sejam pessoas muito mais engajadas em suas atividades.

Conforme Grzybovski e Tedesco, (1998) essas organizações caracterizam-se por compartilharem valores do negocio com valores da família, agregando-os com valores que são adquiridos com o tempo de relacionamento entre funcionários e diretoria. Características que são encontradas nas empresas familiares visando buscar sempre o melhor relacionamento organizacional para a preservação do nome da família e da marca diante da mídia e de seus clientes que são o maior foco da empresa assim como a qualidade de seus produtos e a satisfação do corpo familiar e de colaboradores.

Conforme Grzybovski e Tedesco, (1998) no mundo dinâmico das empresas familiares existem inúmeros pontos que beneficiam e prejudicam a organização podendo influenciar nas relações e decisões da empresa causando conflitos entre familiares e integrantes não pertencentes à família, como clientes e colaboradores.

Os pontos fracos mais comuns são os que surgem quando família e empresa entram em conflitos de interesse quanto a negócios, finanças, controles e Administração. Os pontos fortes por sua vez além de ajudarem no planejamento auxiliam na imagem da empresa perante a sociedade. Esses são o comprometimento pessoal dos integrantes da família, a reputação valiosa da família diante da sociedade, 
bom relacionamento e lealdade dos funcionários, boa relação entre acionistas e dirigentes externos, responsabilidade social visando maior fortalecimento da marca, continuidade tanto da família na direção como continuidade no ramo de atividades.

Todos os pontos tanto fortes, como fracos, são variáveis e podem ocorrer ou não em empresas familiares. A ocorrência desses aspectos varia de acordo com o relacionamento familiar e dos funcionários, podendo ser positivo ou não, interferindo no desenvolvimento empresarial, na competitividade da empresa em seu ramo de atuação e em resultados econômicos.

\section{MOTIVAÇÃO ORGANIZACIONAL}

Conforme BERGAMINI (1997, p. 24) “Acredita-se que a ligação do trabalhador com a empresa seja um elo habitual". Vale salientar que a motivação é resultante de fatores internos, de desejos e de necessidades individuais que cada pessoa, como ser único busca concretizar. O meio externo às organizações não é origem da motivação.

Logo, segundo Aguiar (1997), define que este conceito de motivação é totalmente plausível, ou seja, o colaborador só se sentirá motivado a partir do momento em que houver uma razão, um objetivo, algo a ser atingido. “A organização, enquanto meio social, poderá facilitar ou barrar a realização dos desejos e a satisfação das necessidades" (AGUIAR, 1997, p. 270).

No entendimento de Giovanni (2009), a motivação perpassa, também, pelas relações intra e interpessoais que são desenvolvidas dentro da organização. Dificuldades fazem parte da vida do ser humano e essas relações constituem-se num grande desafio para a humanidade. Contudo, vive-se um momento em que urge indagar sobre as finalidades do agir humano dentro das organizações e o que isso influencia nos resultados. Com as informações descritas surge um novo segmento em que o colaborador tem que aprender a ser corporativo e cooperativo e consequentemente aprender a trabalhar em equipe. Desta forma o profissional de $\mathrm{RH}$ adquire força e em alguns momentos adquire conhecimento para elevar os processos de melhoria dentro das organizações. Como aponta, ainda, o autor, as empresas estão investindo na formação continuada de seus funcionários com o objetivo de desenvolver as competências compatíveis com as novas configurações do processo produtivo, contribuindo na aquisição de novos conhecimentos e na valorização do capital humano. 
Motivação tem o seu foco nos fatores internos ou externos à organização e desta forma, "como as ações individuais nascem em diferentes níveis de profundidade do psiquismo humano, possuem necessariamente um desencadeamento dinâmico qualitativamente diferente" (BERGAMINI, 1997, p.38). Assim é identificado que motivação intrínseca é um conjunto de fatores pessoais ligados diretamente ao indivíduo e a motivação extrínseca remete aos fatores ambientais. Ambos estão relacionados à motivação de cada pessoa, direta ou indiretamente. Os fatores pessoais intrínsecos são aqueles onde o indivíduo é ligado a algum objetivo, às vezes sem nem mesmo saber exatamente o porque. Analisando, pode-se imaginar que a pessoa avalie algo que a motive, pelo simples fato de ser um possível valor pessoal, como a prática de esportes. Os fatores ambientais extrínsecos são aqueles que auxiliam o indivíduo a ser levado a atingir alguma meta através de algo objetivo, por exemplo, um elogio ou uma recompensa. Neste caso, o fator ambiental auxilia na busca da motivação inicial em realizar uma tarefa.

Resumidamente Ribas e Salim (2013) afirmam que a motivação é sustentada por ambos os fatores, intrínsecos e extrínsecos. Retomando o exemplo citado quanto à prática de exercícios, pode-se afirmar que uma pessoa é motivada intrinsecamente a praticar exercícios físicos, por conta dos resultados e valores pessoais, mas ao mesmo tempo obtém estímulos extrínsecos, como o ambiente, os elogios e a recompensa. Esses dois fatores somados aumentarão a busca pelos objetivos pessoais do indivíduo, aumentando sua vontade e motivação. "Satisfação no trabalho é uma variável de atitude que reflete como uma pessoa se sente em relação ao trabalho de forma geral (global) e em seus vários aspectos (facetas)" (SPECTOR, 2002, apud RIBAS e SALIM, 2013, p.21). A motivação tem representado um ponto de equilíbrio com as informações para chegar a compreender melhor o comportamento dos colaboradores dentro da organização de grande ou pequeno porte.

Com grandes ações individuais e profundidade em diferentes níveis, para o individuo entender, é feito um estudo diferente para cada caso, contudo o resultado dos processos com foco no comportamento observado; é fácil a explicação de como se origina e de como pode ocorrer não podendo ser determinado dentro de uma só teoria. As grandes e pequenas empresas precisam investir para entender como seu colaborador 
é motivado, identificando os diferentes aspectos da motivação, pois o que motiva um não motivará o outro; não existem técnicas de motivação, mas a partir de estudos podese entender e aplicar pequenas ações para buscar melhores resultados, verificando se é algo interno (intrínseco) ou externo (extrínseco). (Ribas e Salim, 2013).

\subsection{CONTROLAR VERSUS MOTIVAR}

De acordo com Bergamini (1997), alguns pensadores descrevem que o comportamento do colaborador possa ser adequado, planejado ou mudado de tal forma que possa atingir o resultado esperado pela organização.

\footnotetext{
As diferentes necessidades que coexistem no interior de cada um são comparadas aquilo que também se denomina de desejos ou expectativas e tem como origem carências dos mais diferentes tipos tanto no tocante ao componente físico, como ao psíquico da personalidade. (BERGAMINI, 1997, p.31).
}

Tanto sendo ações positivas quanto negativas como forma de punição que constem no estatuto da empresa, as recompensas adquiridas após um comportamento ou resultado esperado determinam um feedback positivo, já uma punição ou mesmo um direcionamento mais forte pode ser utilizado como feedback negativo sendo mais eficaz após um comportamento inadequado porém, mais corretivo. O objetivo do colaborador nas recompensas como forma de ser reconhecido, tem grande poder para determinar um melhor desempenho. Por isso os estudos sobre motivação comentam que se deva evitar a utilização de feedbacks negativos em excesso para direcionamento dos objetivos.

Segundo STTER e PORTER (1983, apud BERGAMINI, 1997, p 39) “Assim, estritamente falando, a teoria de reforçar não é uma teoria sobre motivação, porque, em si mesma, ela não diz respeito àquilo que energiza ou inicia o comportamento". Assim é possível determinar se as descobertas de tais pensadores explicam muito sobre comportamento humano nas organizações, determinando conhecimento a respeito da motivação. Com todas as ações de alinhamento e cumprimento de metas, acaba sendo verificado um comportamento tipicamente motivacional. Como afirmam MILHOLLAN e FORISHA (1972, apud BERGAMINI, 1997, p.40) “A orientação comportamentalista considera o homem um organismo passivo, governado por estímulos fornecidos pelo 
ambiente externo". Neste caso, o comportamento humano representa simples respostas aos estímulos ambientais, não havendo lugar para se pensar em automotivação.

O uso confuso dos conceitos para o condicionamento e sobre motivação, acaba dando origem a um problema quanto ao verdadeiro entendimento sobre a necessidade de energia interna para o comportamento humano.

Os objetivos motivacionais ou fatores de satisfação passam, assim, para segundo plano, caso se transfira a ideia de atos instintivos, proposto por Bergamini (1997) para a situação motivacional, torna-se viável abandonar a postura que se considera motivação, sendo um fenômeno genérico e inespecífico, isto é, como se fosse um todo indivisível. Um dos conceitos mais frequentemente encontrados no campo das teorias que privilegiam os instintos é o de impulso, termo utilizado para designar um tipo de energia interior que leva os seres vivos à ação (BERGAMINI, 1997, p.89).

Ainda segundo a autora, existe semelhança das ações instintivas, no comportamento motivacional, onde as pessoas necessitam suprir seu estado de carência. Isso só acontecerá pela busca do elemento complementar de contentamento, que também é considerado como plano produtor. Num instante do encontro de necessidade e elemento de satisfação correspondente, leva-se em consideração que tenha acontecido o ato motivacional e, consequentemente se alcança o estado de satisfação.

No entendimento da autora, quando são abordadas as necessidades e a motivação, é analisado o exame das diferenças individuais para se determinar e ter um conhecimento mais objetivo do que se passa no momento com cada colaborador, considerando que o colaborador tenha uma opção de carência ou de necessidade interna que o faça ter uma conduta para alcançar certo objetivo, que caso não seja alcançado não fará ocorrer o ato motivacional.

Em seu artigo "O mito da motivação", Archer (1990) explora de forma clara o aspecto intrínseco da motivação quando diz: "A mais profunda implicação aqui é que ambos os comportamentos, tanto os condicionados como os incondicionados, exigem alguma necessidade ativa intrínseca existente para energizar ou motivar o comportamento". (ARCHER, apud BERGAMINI, 1997, p.92). 
Ele supõe uma compreensão mais efetiva de motivação, conseguida apenas se levada em conta pela dimensão que faz parte das necessidades do indivíduo. Entre satisfação e motivação, Bergamini relaciona as duas partes:

\begin{abstract}
Apesar das dificuldades com pessoas enfrentadas pelas organizações, elas continuam tendo que fazer face ao desafio de atrair sua mão de obra e criar condições para que tais pessoas aí permaneçam desempenhando com eficácia e satisfação as atividades que fazem parte dos seus cargos. Além do mais, as empresas também se veem diante do desafio de utilizar o potencial produtivo e criativo existente dentro de cada pessoa, transformando-o em comportamento naturalmente espontâneo, oportunamente construtivo e eficazmente inovador (BERGAMINI, 1997, pg. 25).
\end{abstract}

No entendimento de Bergamini (1997), é difícil se ter conhecimento daquilo que se entende como motivação autêntica em caso de não ter em mente as explorações realizadas, assim a teoria analítica oferece compreensão do ser humano em suas emoções, em relação ao conhecimento do comportamento humano, seguia-se principalmente a orientação ditada pela neurofisiologia para entender melhor as bases sobre as quais se apoiavam os diferentes tipos de reações das pessoas observadas. $\mathrm{Na}$ pesquisa coerente entre os fatos já vivenciados pelo indivíduo, a análise teórica chega a descobrir a infância como relevante e indiscutível no desenvolvimento de suas características.

Verificando os estudos elaborados com os fundamentos de Freud, além de se compreender os valores dos instintos e das emoções, ocorre a descoberta do fator conhecimento como sendo integrante do processo da motivação. A descoberta oferecida pelos fatos passados criará um processo que poderá facilitar ou dificultar os ajustes da motivação.

\title{
4. TEORIAS MOTIVACIONAIS
}

As Teorias Motivacionais abordadas nesta pesquisa são conceituadas e entendidas como parte fundamental para o desenvolvimento da relação Motivação x Colaborador, assim visando que se obtenha um parecer fundamental sobre a importância do tema abordado. As teorias de cunho motivacional estudam e apresentam fatores que tentam explicar como as pessoas agem em relação a seu comportamento. Com base nos pensadores abordados, busca-se aplicar as suas teorias no ambiente organizacional. 


\subsection{TEORIA DE ABRAHAM MASLOW}

Conforme Aguiar (2005), Maslow foi psicólogo clinico e um dos pioneiros no desenvolvimento da teoria das necessidades, trazendo enormes contribuições às organizações. A teoria da Hierarquia das Necessidades de Maslow é sem dúvida, uma das teorias da Motivação mais conhecidas. Esta teoria figura em dois pontos focais principais: 1. As pessoas são organismos motivados pelo desejo de satisfazer determinado tipo de necessidades; 2. Neste segundo divisor, Maslow acredita que quando as necessidades do indivíduo não são atendidas, isto geraria um estado de insatisfação e tensão, fazendo com que este se comporte de maneira a tentar reduzir tal tensão, tentando recuperar o equilíbrio perdido. Quando satisfeita a carência, esta perde o potencial e a força motivadora que agiam sobre o individuo.

Com base nesses pontos, a teoria das necessidades de Maslow propunha a existência de cinco tipos de necessidades, divididas em forma de pirâmide. Maslow dividiu ainda as cinco necessidades em dois grandes grupos: necessidades de ordem superior ou secundárias, e as de ordem inferior ou primárias. Necessidades de segurança e fisiológicas são de ordem inferior, sendo as outras necessidades de ordem superior. $\mathrm{O}$ que diferencia as duas ordens é que as de nível superior são intrínsecas, enquanto as de nível inferior são extrínsecas, ou seja, para a organização suprir as necessidades de nível inferior é praticamente uma obrigação, pois dizem respeito ao salário, local de trabalho, máquinas ou softwares, e outros.

Nas organizações em geral, motivar o colaborador através da satisfação das necessidades de nível inferior é simples. Porém as necessidades de nível superior são de difícil compreensão para as organizações. Muitas vezes quando se supre uma necessidade de nível superior, outras aparecem facilmente, pois essas necessidades são infinitas. As organizações devem proporcionar um ambiente de trabalho propício e competitivo para que essas necessidades cheguem ao menos, próximo do almejado pelo colaborador. A teoria da Hierarquia das Necessidades de Maslow tem recebido grande aceitação por parte dos gestores, porém se se fizer uma investigação a fundo, se verá que ela fica apenas na "teoria", que na prática, as organizações em geral ainda não fecharam os olhos para o cifrão, ou seja, o dinheiro, e que o colaborador ainda é visto 
como robô, estando ali apenas para gerar lucros, e caso isso não ocorra, a punição, ou feedback negativo é o primeiro passo que a empresa toma em relação ao indivíduo.

Figura 1 - Teoria das Necessidades de Maslow

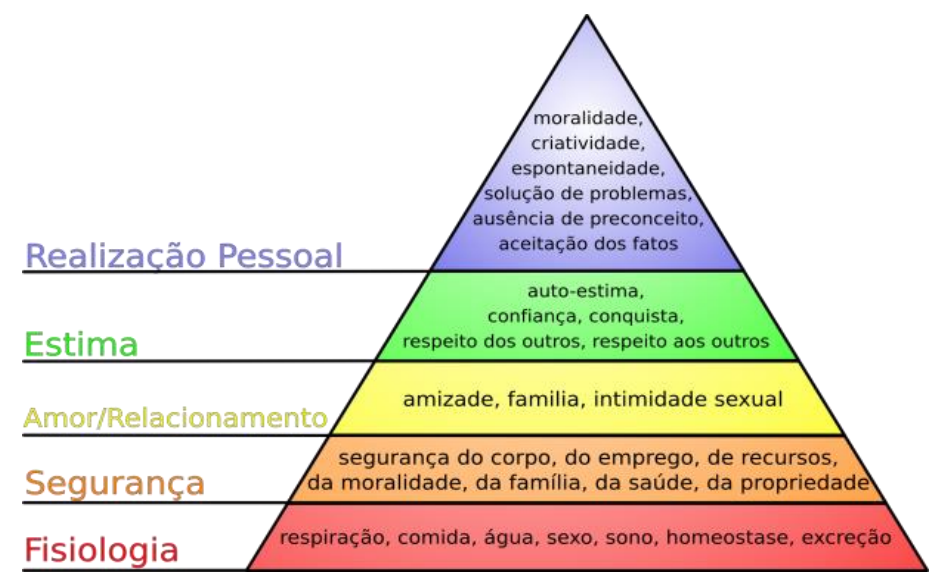

Fonte: AGUIAR, 2005, p. 357.

Conforme a figura 1, sobre a Hierarquia das Necessidades de Maslow e sua definição; as Necessidades Fisiológicas são relacionadas às necessidades do organismo, e são as principais prioridades do ser humano. Entre elas estão respirar e se alimentar. As Necessidades de Segurança envolvem a estabilidade básica que o ser humano deseja ter. Por exemplo, segurança física, segurança de recursos financeiros, segurança da família e de saúde. Um benefício como assistência médica é um dos exemplos que pode ser aplicado na empresa. As Necessidades de Amor ou Sociais surgem após as duas primeiras categorias serem supridas e o indivíduo passa a ter necessidades relacionadas à atividade social, como amizades, aceitação social, suporte familiar e amor. Esta necessidade é particular para cada indivíduo, porém na empresa diz respeito ao trabalho em equipe, por exemplo. (SOUZA, 2014). As Necessidades de Status e Estima, indicam que todo ser humano gosta de ser respeitado e bem visto. Ser reconhecido como uma pessoa competente e capaz. Em alguns casos pode levar a exageros como arrogância e complexo de superioridade. É preciso ter cautela. Promoções em geral, podem suprir esta necessidade. As Necessidades de Auto Realização são necessidades instintivas do ser humano. Todos gostam de sentir que estão fazendo o melhor com suas habilidades e superando desafios. As pessoas neste nível de necessidades gostam de resolver problemas, possuem um senso de moralidade e gostam de ajudar aos outros. Suprir esta 
necessidade equivale a atingir o mais alto potencial da pessoa numa organização, conforme Souza (2014).

\subsection{TEORIA DAS NECESSIDADES DE HENRY MURRAY}

A teoria de Murray sobre as necessidades manifestadas define as necessidades como preocupações recorrentes com determinadas metas ou situações finais. Murray desenvolveu esta Teoria na década de 30, com auxilio de um grupo da Harvard Psychological Clinic. Conforme Bergamini (1997) cada necessidade é composta por dois elementos. O primeiro diz respeito à ordem qualitativa, representada pelo objeto para o qual a necessidade esta voltada. O segundo descreve a intensidade ou força da necessidade daquele objeto particular. Ao contrario de Maslow, Murray considerava que as necessidades eram aprendidas e que nada tinham a ver com a genética. Ainda conforme Bergamini (1997), as necessidades listadas por Murray não estavam organizadas de maneira hierárquica, ao contrário da Teoria de Maslow. Dentro dessa concepção, o indivíduo poderia possuir mais de uma necessidade ao mesmo tempo.

\subsection{TEORIA DAS NECESSIDADES DE MCCLELLAND}

David McClelland (1917-1998), conhecido psicólogo, estudou a relação entre necessidades e comportamento desde o final da década de 1940. De acordo com Aguiar (2005), McClelland criou sua teoria de necessidade de realização, onde relata que o indivíduo se realiza naquilo que faz e não na recompensa que recebe. Portanto, isso justifica o individualismo e egoísmo do indivíduo, pois quando almeja alcançar seus objetivos, não mede esforços. Ele cita que tudo se justifica, à medida que o indivíduo se realiza. Após estudos realizados, inclusive no Brasil, com adolescentes e com grupos de executivos de diferentes culturas, McClelland defende que o indivíduo tem necessidade de realização, de poder e de afiliação em graus diferentes. Segundo ele, pessoas que tem necessidade de realização, rendem mais em determinadas situações. Aguiar (2005) apresenta as descrições de cada uma das necessidades expostas na Teoria de McClelland, a Necessidade de realização é o impulso de lutar pelo sucesso, de alcançálo, de exceder e de se sair bem em relação ao que é padronizado. Na Necessidade de poder os indivíduos estabelecem como metas e objetivos pessoais o alcance do poder, 
os padrões de sua realização pouco importa para eles. E na Necessidade de afiliação os indivíduos necessitam de relações interpessoais, próximas e o mais amigáveis possível.

\section{LIDERANÇA}

Segundo conceitos de vários autores, Souza destaca em seu artigo:

Liderança é um tipo de relacionamento de poder caracterizado pela percepção dos membros do grupo no sentido de que outro membro do grupo tem o direito de prescrever padrões de comportamento na posição daquele que dirige, no que diz respeito à sua atividade na qualidade do membro do grupo (SOUZA apud JANDA, 1960, p. 35).

Para Ferreira, Reis e Pereira (2011), Liderança vem de uma característica de capacitação da melhor escolha. Isso auxilia na flexibilização em tomadas de decisões que são apoiadas por todos dentro do grupo. "A liderança se refere à qualidade do comportamento dos indivíduos, através do qual eles guiam pessoas ou suas atividades em esforço organizado". (BARNARD, 1962, p. 82 a 83 apud FERREIRA, REIS e PEREIRA, 2011). Determinar uma consolidada liderança vai depender de três fatores essenciais: o indivíduo, seus seguidores e as condições nas quais elas acontecem no ambiente. Dessa forma, executar o papel de líder deve-se ao entendimento nas organizações, seus colaboradores, que fazem parte delas e as interações pessoais que podem estimular os melhores resultados em sincronia de todos.

A liderança se define em praticar o comando com as pessoas, enquanto motivação é uma "espécie de energia psicológica ou tensão que põe em movimento o organismo humano, determinando um dado comportamento" (PEREIRA 2008). Então ele entendeu que os dois juntos significam uma ação de gerenciar os colaboradores, buscando esse esforço e aplicando de forma pessoal e em benefício próprio e mútuo, inserido num determinado grupo. Todos os lideres tem o grande desafio de manter essas pessoas motivadas, sabendo que sua gestão dependerá de uma análise ambiental de cada um, respeitando suas diferenças ou da equipe, através de seus pontos fortes, fracos e de suas oportunidades, ameaças (SWOT). Quanto mais a gestão estiver informada sobre as ferramentas de mercado (treinamentos, palestras, bibliografias entre outros) e souber 
como aplicá-las a seus colaboradores, maior será a chance de se conseguir o sucesso nos resultados almejados.

As características de um líder gestor de empresa familiar são elencadas dessa forma:

Demonstram ser poderosos e fazem notar e transcender essa dimensão de poder. - Criam uma zona de proteção contra aqueles que atacam o seu poderio através de penalidades. Protegem-se de qualquer oposição interna ou externa a fim de obterem maior coesão do grupo. - Exigem absoluta lealdade a suas ideias e conceitos por parte do grupo (empresarial e familiar). - Valorizam somente as suas virtudes e negam seus defeitos. Definem-se como portadores de uma única verdade, constituindo-se na garantia da continuidade da empresa. - Eliminam ou diluem a interação com outros grupos, fato que reforça suas. - Características negativas e gera maiores distorções na sua percepção da realidade. - Aplicam um regime ad hoc de prêmios e castigos para influenciar melhor o grupo, oferecendo métodos objetivos de avaliação de desempenho (GRZYBOVSKI e TEDESCO, 1998, p. 49).

Como Gil (2001) em um mundo tão competitivo e cada vez mais concorrido, exige-se cada vez mais altos índices de motivação dos colaboradores, visando o crescimento da empresa e do colaborador, pois desta forma podem-se desenvolver lideres capazes de atender a alta gestão. Como as empresas estão visando e valorizando o comprometimento de seus colaboradores já que são cada vez mais convidados a fazer parte do desenvolvimento de soluções, é nessas pessoas que as empresas tendem a investir. A motivação por sua vez é a chave para buscar e desenvolver o comprometimento de seus liderados; pensando como empresa é muito mais fácil conseguir pessoas capazes do que pessoas comprometidas; se se observar como a rotatividade no mercado está cada vez mais alta, por esse motivo é que de fato se identificam certos fatores que podem motivar o colaborador a permanecer na empresa e buscar seu crescimento profissional. Gil (2001) relata que com técnicas aprimoradas de motivação, vê-se que a motivação é um estimulo a fazer diferente ou superar expectativas, sendo claras as metas e o colaborador sabendo onde pode chegar, é um fator de diferencial para ser um motivador ou motivado, os seres humanos são motivados tanto no profissional quanto no pessoal quando têm alguma meta a ser atingida ou algum destino que prefiram. $\mathrm{O}$ autor, observa que para Freud "boa parte da motivação humana localiza-se abaixo do nivel da consciencia conforme a analogia do Iceberg apresentada por ele" (GIL, 2001, p. 202). 


\section{ESTUDO DE CASO}

A empresa pesquisada situa-se em São Paulo, Capital, nos bairros da Vila Olímpia e da Lapa, atua na área de franquias, onde comercializa grandes marcas, de vários segmentos diferentes, atendendo investidores interessados em montar seu próprio negócio. A empresa dispõe de equipe de colaboradores, divididos nos dois locais de sua instalação, que por sua vez, atendem de forma prática os investidores. Na Vila Olímpia, a empresa normalmente atende investidores que vem de outros Estados, por estar localizada próxima ao aeroporto. O diferencial desta filial é ter um showroom instalado dentro da empresa, onde os investidores podem se imaginar em seu próprio negócio, além de entender melhor as instalações e padrões da mesma.

Na filial da Lapa, atendem os investidores que residem em São Paulo e buscam praticidade, localização e rápido atendimento. Nesta filial encontra-se a maior parte dos colaboradores, além de possuir uma estrutura mais completa. A estrutura organizacional da empresa é composta pelos diretores, além dos colaboradores, distribuídos entre Recursos Humanos, Suporte, Tecnologia da Informação, Comercial, Financeiro, Recepção e Atendimento.

Nas reuniões com o diretor da empresa pesquisada atendeu e orientou esta pesquisa, apresentando a estrutura das unidades, departamentos, modo de trabalho, políticas etc.. Observa-se que os setores de vendas representam cerca de $60 \%$ da estrutura total da companhia. O primeiro atendimento, as negociações, visitas e apresentações das propostas são realizados pelo setor de vendas, que conta com suporte das demais áreas da empresa para que se concretizem os negócios.

\subsection{METODOLOGIA DA PESQUISA}

A pesquisa foi realizada a fim de identificar o clima organizacional da empresa, além de verificar os pontos fortes e fracos da organização, no que tange a um ambiente motivado. Após visitas técnicas nas unidades, com supervisão do diretor, entendeu-se o negócio da empresa e desenvolveu-se o questionário aplicado, que tem o propósito de colher e consolidar a visão dos colaboradores da organização. Durante dez dias, entre os meses de agosto e setembro de 2014, os componentes desta pesquisa estiveram na 
empresa, visitando as duas unidades físicas instaladas em São Paulo, nas regiões da Vila Olímpia e Lapa. Responderam ao questionário 63 colaboradores (Adendo A).

Nenhum dos colaboradores foi obrigado a responder, sendo que não foi registrado o nome ou qualquer outra informação que identifique o entrevistado, portanto foi garantida a confidencialidade e os procedimentos éticos. O nome da empresa não foi divulgado para garantir a confidencialidade.

\subsection{RESULTADOS DA PESQUISA}

Foram Entrevistados 63 colaboradores de um total de 74 funcionários operacionais.

Conforme a pesquisa pode-se observar que:

- $\quad$ O nível de contentamento dos colaboradores em relação às suas responsabilidades na empresa, sendo que mais da metade dos entrevistados (52\%) acreditam que seu trabalho contribui para o crescimento da empresa, mas $45 \%$ sentemse pressionados para realizar suas tarefas.

- $\quad$ Em relação à realização profissional, 65\% destacam estão satisfeitos com sua ocupação e $70 \%$ se sentem seguros para continuar na empresa. Os resultados positivos são excelentes para a empresa, pois funcionários engajados e satisfeitos, tendem a produzir mais.

- $\quad$ Em relação à comunicação, $11 \%$ dos colaboradores considera que a empresa não se comunica de forma correta. Número este que pode ser visto como relativamente alto, analisando a questão importante em confronto com os relacionamentos interpessoais internos. Este é um fator importante para o sucesso da empresa, pois uma boa comunicação pode gerar melhores resultados. .

- Ao analisar a visão de futuro dos colaboradores em relação à empresa, 76\% dos colaboradores considera que há oportunidades de crescimento, com um resultado satisfatório e $66 \%$ considera que a empresa oferece ferramentas para o desenvolvimento profissional.

- Há números de aceitação relativamente altos quanto à visão de aptidão do superior imediato 55\%. Há, porém, $23 \%$ que optaram negativamente, outros $22 \%$ 
afirmaram não ter opinião. Nas visitas, percebeu-se que os colaboradores têm medo dos gestores, quando estão sob pressão, fato este que pode estar ligado às metas de vendas.

- $\quad$ Sobre a comunicação entre colegas de trabalho, as respostas não foram positivas. Quando houve conversas com alguns colaboradores, estes reclamaram que os departamentos administrativos, se reportam a eles de forma brusca, como se fossem melhores por causa de sua posição. Para atendê-los estabeleceram até mesmo regras, como horários e datas propícias.

- $\quad$ O panorama sobre a valorização profissional demonstra que a maioria dos entrevistados entende que a empresa reconhece os bons funcionários. Fator este, preponderante para o crescimento pessoal e profissional dos colaboradores, comparando com a motivação dos funcionários, que se sentem valorizados e estão satisfeitos com a empresa, o que pode tornar o ambiente agradável e produtivo.

- A área de Treinamento e Desenvolvimento é bem aceita pelos colaboradores, sendo que grande parte deles está satisfeita com a forma como a empresa lida com o desenvolvimento dos colaboradores em relação à aprendizagem técnica.

- Os colaboradores reclamam das condições de trabalho em relação à temperatura. Eles consideram que, por vezes, o local é muito frio ou muito quente, não chegando a uma temperatura agradável que fique a gosto de todos. Isso ocorre por conta da regulagem do ar condicionado. Quanto à higiene, disseram que a limpeza dos banheiros às vezes é precária, acumulando lixo e ficando horas sem a devida limpeza.

- $\quad$ Existe uma parcela considerável que gosta de trabalhar na empresa (64\%) e que $60 \%$ indicaria um conhecido para trabalhar na organização. Este fato com certeza agrega valor à imagem da empresa, principalmente no ramo onde atua, que conta com poucos concorrentes.

- $\quad$ Referente aos benefícios; foram abordados dois deles na pesquisa: cesta básica e refeição oferecida no local de trabalho. Os produtos da cesta básica têm uma ótima aceitação, quase todos estão muito satisfeitos. Outro ponto analisado foi em relação à comida servida, que os colaboradores contam com o beneficio de vale refeição. Cabe ressaltar que as refeições são servidas por empresa terceirizada, contratada para atender esta demanda. 
- A maioria dos colaboradores não se sente seguro para efetuar as vendas. Esse fato ocorre devido à vasta gama de produtos e serviços oferecidos, pois mesmo sendo treinados para efetuar vendas de determinados produtos, são obrigados a vender todos os produtos da carteira, não se tornando especialistas em apenas um tipo de franquia ou serviço. Também alegaram que não possuem o devido suporte para realizar as transações de vendas, com um sistema de banco de dados lento que impacta no rápido atendimento.

\section{ANÁLISE E DISCUSSÃO}

Para motivar é preciso identificar o que motiva cada pessoa. Apesar de algumas respostas negativas; conforme demonstram os resultados da pesquisa, a empresa demonstrou algumas qualidades, como o suporte e incentivo aos seus colaboradores, oferecendo boas condições de trabalho. A motivação dos colaboradores na empresa começa primeiramente com o respeito entre os colegas de trabalho, constatação que se notou nas visitas realizadas à empresa, além da analise das respostas obtidas por meio das respostas dos questionários. Por isso, é necessário que o departamento de Recursos Humanos tenha controle quanto a essa situação, inovando a maneira de gerir pessoas e reter talentos, oferecendo cada vez mais, melhores condições de trabalho. Mesmo constando do questionário aplicado, apenas em duas perguntas específicas e diretas foram recebidas algumas reclamações apontadas pelos colaboradores do departamento de vendas, as quais dizem respeito ao método de atendimento e venda inicial, onde não existe uma definição de equipe especifica para cada tipo de franquia. O vendedor que atender a ligação, independentemente de ser ele ou não o representante daquela marca, é o responsável por vendê-la, efetuando o atendimento de praxe. Isso torna o processo de venda inicial realizado via telefone, uma atividade não atribuída a um especialista, pois a equipe embora atenda todas as áreas e tipos de franquias, não possui um colaborador dedicado apenas àquela venda da marca procurada pelo possível cliente.

Procurou-se entender o motivo pelo qual este tipo de atendimento é utilizado na empresa e segundo o diretor isso ocorre há cerca de 10 meses, em fase experimental por conta de problemas no passado, ocorridos com este departamento específico de vendas. Tal problema baseia-se no fato de que antes o atendimento era realizado por vendedores treinados apenas para atender uma marca específica. Contudo, embora o atendimento 
fosse feito de forma eficaz, nem sempre, independente da vontade do vendedor, ele conseguia atender os investidores de forma eficiente, pois por diversas vezes, o investidor o buscava e por motivos da própria empresa, eles estavam fora, realizando atendimento externo, auxiliando outros possíveis franqueados ou em reuniões. Portanto tal mudança, segundo o diretor, foi necessária, em seu ponto de vista, visando o atendimento ágil e eficaz da empresa para com os possíveis franqueados.

Adotou-se, ainda, esta nova medida, que todos os vendedores atendam todas as marcas, pois assim acredita-se que os investidores ficam satisfeitos em ser atendidos prontamente pelo vendedor que estiver de plantão. Conforme anteriormente destacado, de todos os setores visitados, o que mais apresentou resultados negativos é o de vendas, por conta do problema anteriormente apontado, logo este departamento pode ser uma área que necessite de ajustes em seus processos.

A empresa tem boas intenções, realiza periodicamente treinamentos, palestras motivacionais, workshops, além de possuir uma excelente politica de comissões e prêmios às equipes que mais se destacam. Também realiza festas esporádicas, como por exemplo, para os aniversariantes, sempre na última sexta-feira do mês que é dedicada às festas da equipe. Presenteia os colaboradores em datas especiais como dia dos pais, dia da mulher, dia das mães, Páscoa, Natal etc. Qualidade de vida envolve o bem estar físico, mental, psicológico e emocional, além de relacionamentos sociais, com família e amigos, saúde, educação, poder de compra e outros fatores. Para motivar, acredita-se que ações simples, porém cuidadosas, auxiliam o envolvimento e comprometimento de toda a equipe.

\subsection{RESPONSABILIDADES}

As responsabilidades na empresa compreendem o nível de trabalho que é executado diariamente, a qualidade e a importância que esse trabalho traz para a organização. Todo trabalho é importante, caso contrário, a empresa não pagaria por ele. Entende-se que quando o colaborador está insatisfeito com suas tarefas, primeiramente é porque não se identifica com elas e em último caso, porque seu gestor está falhando na hora de orientar o que deve ser feito ou controlando as atividades. O colaborador passa a maior parte do tempo na empresa e por isso costuma-se dizer que é sua segunda casa. 
Por isso a comunicação entre as pessoas da organização deve ser saudável, a ponto do colaborador se desligar de sua vida pessoal enquanto trabalha; produzindo da melhor maneira possível. As pessoas ao ingressarem em uma organização, sonham um dia, em ter sucesso e reconhecimento. A carreira é a sustentação para o desenvolvimento do bom trabalho. Os indivíduos querem ser bem sucedidos, ou ao menos estar contentes com sua posição na empresa. Quando isso acontece a empresa ganha prestígio por parte de seus colaboradores e estes desenvolvem mais e melhor seu trabalho por conta da valorização existente na organização.

Da mesma forma que o relacionamento entre os colegas de trabalho, o relacionamento com a supervisão deve ser saudável. É difícil uma organização se sustentar, quando ela é dominadora. É necessário haver respeito mútuo, consideração e apreço por parte de todos, para que o ambiente de trabalho seja saudável e produtivo. Treinar e desenvolver colaboradores é suprir suas carências em relação ao trabalho ou buscar de forma clara e objetiva o aprimoramento das tarefas. O Departamento de Recursos Humanos está bem preparado para atender aos requisitos de treinamento e desenvolvimento. As palestras, cursos e treinamentos oferecidos são bem aceitos e

refletem o bom desempenho aos colaboradores. É claro que também é um quesito que sempre será alvo de questionamentos e descontentamentos, mas pode-se verificar que é bem administrado pelo Departamento de Recursos. A empresa, embora com pouco tempo no mercado, é, hoje, uma organização competitiva e em constante crescimento.

\subsection{PREPARAÇÃo E PROPOSTA PARA IMPLANTAÇÃo DE SALA DE JOGOS E TV}

Apoiado na ideia de melhorias ambientais para a empresa e de acordo com o trabalho estressante trazido pelas pressões de resultados e vendas, sugeriu-se a criação de uma sala, onde seria disponibilizada uma estrutura para os funcionários descansarem pós-almoço ou em um momento de estresse, com disponibilidade de televisão, revistas, jornais, café e água. Hoje a empresa conta com um excelente espaço na região da Lapa, em prédio próprio, o que facilitaria a implantação deste espaço. Nas visitas percebeu-se que o setor de vendas é o que mais sofre pressão e para tanto, necessitaria de atenção especial. Fato este facilmente comprovado quando se nota que o grande responsável 
pela prosperidade da empresa é este departamento. É importante que o RH dê ênfase ao colaborador, deixando-o à vontade para expor suas ideias e propor melhorias. Os esforços necessários agora renderão grandes frutos no futuro. Investir no colaborador nada mais é do que cuidar das finanças e do futuro da empresa, pois são eles os responsáveis diretos pela prosperidade de qualquer organização, por isso sua importância é enorme. Continuar investindo em treinamento e desenvolvimento é acima de tudo necessário. Este é um ponto forte da empresa e não pode deixar de ser medido e monitorado. Sabe-se que o conhecimento gera respeito, quanto mais valorizados nesta parte, mais os colaboradores terão argumentos para melhorar os processos e contribuir com sugestões criativas.

\section{CONSIDERAÇÕES FINAIS}

Motivar é nada mais do que sustentar, dar motivo, dar ideia de movimento. A Organização precisa motivar os colaboradores, que são os principais responsáveis pelo sucesso da empresa. Motivados pelo universo empresarial, após alguns estudos sobre qual tema escolher para escrever este artigo, deparou-se em meio às buscas com o tema motivação em empresas familiares, o que instigou o fato de descobrir se este tipo de situação interferiria diretamente nos funcionários da empresa, por se tratar de empresa familiar, ou seja, na relação funcionário-empresa.

A empresa trabalha de acordo com os padrões motivacionais em que acredita. Conforme o resultado do questionário aplicado na empresa, foi notado que a maioria dos colaboradores está satisfeita com a atuação da mesma, no entanto, há um aspecto que não agrada a todos os colaboradores, que é o sistema de atendimento aos investidores interessados nas franquias da rede.

Com a pesquisa de clima organizacional, foi possível fazer um levantamento significativo, onde se pode diagnosticar que faltam alguns pequenos ajustes que talvez possam contribuir com um melhor ambiente para todos. Por meio da pesquisa e com auxilio dos materiais bibliográficos e estudo de caso, pode-se responder e atender aos objetivos gerais e específicos deste artigo. A maior dificuldade encontrada foi quanto ao problema central, que trata do setor de vendas. De acordo com a conduta da empresa escolhida para se executar a pesquisa de campo, os interessados entram em contato com ela e o atendimento é feito prontamente, pelo colaborador de vendas disponível no 
momento. Após varias conversas com o diretor, a fim de entender de fato o funcionamento desse departamento, e como se poderia auxilia-los no seu desenvolvimento e melhorias e após o término das pesquisas e da compilação de informações, pode-se desenhar de forma satisfatória, algumas sugestões que visam ajudar o departamento e automaticamente a empresa e os colaboradores.

Após as pesquisas, somadas ao estudo de caso, pode-se dizer que a gestão de empresas familiares é um grande mito a ser estudado, pois ser o dono de seu próprio negócio faz com que se modifiquem os ensinamentos adquiridos em anos de estudo ou de experiência. Afirmar que a empresa familiar é diferenciada pela gestão é uma afirmação certa, pois seus administradores seguem mais seus instintos do que o aprendizado obtido e isso as faz bem sucedidas.

Os colaboradores acreditam que se cada um, fosse responsável por uma marca específica, aproveitariam melhor o atendimento; e com exclusividade, atenderiam melhor o investidor e se esforçariam mais. Indagados se já tinham proposto uma solução, ou proposta diferente ao responsável pela empresa, para sanar este desconforto e melhorar a produção na área de vendas, a maioria dos colaboradores informou que a devolutiva, é que não é possível individualizar os atendimentos, pois em muitos momentos, determinado gerente não esta presente na empresa, então geraria um desconforto ao investidor, fazendo-o aguardar até o gerente específico da marca de interesse, estar disponível para atendê-lo e gerar assim um déficit de atendimento e espera indesejável, para com o investidor.

A escolha das várias Teorias sobre Motivação se fez necessária para identificar a relação direta que se encontra no fato de a empresa ser dirigida por membros de uma mesma família. Até que ponto, essa questão interferiria no bom andamento da empresa, já que se dá pelo fato desta palavra estar relacionada também a fatores pessoais, ou seja, buscar informações que visassem proporcionar respostas referentes a até que ponto a motivação na empresa interfere nas ações dos colaboradores dentro e fora dela. Com base nos estudos da pirâmide de Maslow para definir o arcabouço do trabalho, buscouse explanar o processo que descreve as necessidades que cada indivíduo tem de sanar as inferiores, para depois passar para as superiores, ou seja, como é entendida a palavra motivação para colaboradores de determinada empresa, neste caso familiar, em relação 
à sua vida e necessidades pessoais e profissionais, baseado em grandes teóricos como Maslow e Herzberg.

De acordo com a teoria de Herzberg, a aplicação de um de seus fatores, no caso o motivacional, muito contribuiria para solucionar as divergências que a empresa vem sofrendo, segundo os colaboradores, pois de acordo com os fatores motivacionais, o bom andamento da empresa na área de vendas, se dá pelos fatores principais, que são o ambiente propício para a realização das tarefas, o aprimoramento dos colaboradores e o designio de materiais necessários à realização do trabalho. Desta forma, o vendedor poderia atender o cliente em qualquer horário do dia via vídeo conferência, Skype, mensagens e etc. Para tanto, é necessário que a empresa forneça notebooks, telefones e eventuais materiais necessários, para que o trabalho seja realizado.

Referente aos estudos realizados, acredita-se que a aplicabilidade dos fatores motivacionais de Herzberg na Empresa contribuiria muito e seria de grande ajuda para a relação funcionário-empresa, pois com as condições necessárias citadas por Herzberg, aplicadas à empresa, se sanaria o problema do qual os funcionários se queixam e todos poderiam atender os clientes específicos de suas marcas com máxima eficiência e de acordo com os materiais disponibilizados pela empresa. Considerando que a empresa que está disposta a crescer e ser cada vez mais competitiva, pode-se prever que o plano de melhorias em caso de aplicação, traria resultados positivos à empresa, agregando maior valor à marca e trabalhando o lado pessoal do colaborador de um modo que ocorreria uma grande valorização e reconhecimento de cada um deles. De acordo com as hipóteses levantadas neste artigo, que giram em torno das teorias de Maslow e Herzberg, em caso de aplicação por parte da empresa, se teria em tese, os colaboradores mais valorizados e bem quistos, automaticamente aumentando a produtividade da empresa. Não que a empresa não os valorize, mas certamente teriam um maior reconhecimento e condições de trabalho mais adequadas. Para isso, o projeto foi apresentado de forma a contribuir para que a empresa tenha um ambiente mais motivador do que tem hoje, dando maior ênfase ao lado pessoal dos colaboradores, pois estes também possuem suas necessidades não somente ligadas ao ambiente empresarial.

Pode-se deduzir que motivação é a ferramenta mais importante para qualquer organização. Sem motivação, não existe trabalho bem feito e muito menos vontade de 
realiza-lo. O trabalho pode ser eficiente, mas não será eficaz, já que os dois dependem um do outro.

\section{REFERÊNCIAS}

AGUIAR, M. A. F. Psicologia Aplicada à Administração: uma abordagem interdisciplinar. São Paulo: Saraiva, 2005.

BERGAMINI, C. W. Motivação nas organizações. São Paulo: Atlas, 1997.

BRASIL. Lei $\mathrm{N}^{\mathrm{ao}} 10.406$ de Janeiro de 2002. Institui o Código Civil Brasileiro. Disponível em: < $\quad$ http://www. planalto.gov.br/ccivil_03/leis/2002/110406compilada.htm>. Acesso em 11/08/2014.

BRASIL. Mapa das Micro e Pequenas Empresas. Disponível em: <http://www.brasil. gov.br/economia-e-emprego/2012/02/o-mapa-das-micro-e-pequenas-empresas $>$. Acesso em $08 / 08 / 2014$.

CHIAVENATO, I. Gestão de Pessoas: O novo papel dos Recursos Humanos nas organizações - 3. Ed. Rio de Janeiro: Elsevier, 2008.

CHIAVENATO, I. Recursos Humanos - O Capital humano das Organizações. 9 Ed. Rio de Janeiro: Elsevier, 2009

DIREITONET. Conceito de empresa. Disponível em: <http://www.direitonet.com.br/ resumos/exibir/843/Conceito-de-empresa>. Acesso em 08/08/2014.

FERREIRA, A. A.; REIS, A. C. F.; PEREIRA, M. I. Gestão Empresarial: De Taylor aos nossos dias. São Paulo: Cengage Learning, 2011.

GIL, A. C. Gestão de Pessoas: enfoque nos papéis. São Paulo: Atlas, 2001.

GIL, A. C. Gestão de Pessoas: Enfoque nos papéis profissionais. São Paulo: Atlas, 2006.

GRZYBOVSKI. D.; TEDESCO, J. C. Empresa Familiar X competitividade: Tendências e racionalidade de conflitos. Teor. Evid. Econ., Passo Fundo, V. 6, N. 11, 1998

HERSEY, P.; BLANCHARD, K. H. Psicologia para administradores: a teoria e as técnicas da liderança situacional. 4. ed. São Paulo: E.P.U., 2011.

MACEDO, José Ferreira, Sucessão na empresa familiar. Ed. Nobel. São Paulo, 2009.

MARRAS, J. P. Administração de Recursos Humanos: do operacional ao estratégico. 14. ed. São Paulo: Saraiva, 2011. 
PAULO, R. P. Gestão de Pessoas Liderança: A alma do negócio: Escola Apas Editora Globaltec Ltda.]

PORTAL DO EMPREENDEDOR. Definição do Microempreendedor Individual. Disponível em: <http://www.portaldoempreendedor.gov.br/mei-microempreendedorindividual $>$. Acesso em 11/08/2014.

PORTAL DO EMPREENDEDOR. Definição por Sociedade Anônima. Disponível: $<$ http://www.portaldoempreendedor.gov.br/outras-naturezas-juridicas/sociedade-anoni

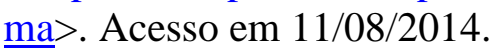

PORTAL DO EMPREENDEDOR. Definição de Sociedade em Comandita Simples. Disponível em: $\quad$ http://www.portaldoempreendedor.gov.br/outras-naturezasjuridicas/sociedade-por-comandita-simples $>$. Acesso em 11/08/2014.

PORTAL DO EMPREENDEDOR. Definição de EIRELI. Disponível em: <http://www.portal doempreendedor.gov.br/eireli >. Acesso em 11/08/2014.

PORTAL DO EMPREENDEDOR. Enquadramento de Empresário como ME ou EPP. Disponível em: <http://www.portaldoempreendedor.gov.br/empresario-individual/memicroempresa-epp-empresa-depeque no- porte/?searchterm=epp $>$. Acesso em $11 / 08 / 2014$.

PORTAL DO EMPREENDEDOR. Requisitos em impedimentos pessoais. Disponível em: $\quad<$ http://www.portaldoempreendedor.gov.br/empresario-individual/requisitos-eimpedimentos-pessoais>. Acesso em 11/08/2014.

PORTAL DO EMPREENDEDOR. Sociedade Comandita Simples. Disponível em: < http://www.portaldoempreendedor.gov.br/sociedade-por-comandita-simples $>11 / 08 / 14$.

PORTAL DO EMPREENDEDOR. Tipos de Empresa. Disponível em: <http://www.portal doempreendedor.gov.br/sobre-portal/tipos-de-empresa >. Acesso em $11 / 08 / 2014$.

REVISTA PEGN. Estatísticas sobre empresas brasileiras. Disponível em: <http://revistapegn.globo.com/Revista/Common/0,EMI317221-17180,00-

DAS+EMPRESAS+BRASILEIRAS+FECHAM+AS+PORTAS+DEPOIS+DE+TRES+ ANOS.html>. Acesso em 08/08/2014.

RIBEIRO, A. DE L. Gestão de Pessoas. São Paulo. Saraiva, 2005.

RH.COM.BR. Liderança e Motivação. Disponível em: < $\underline{\text { http://www.rh.com.br/Portal/ }}$ Lideranca/Artigo/5159/lideranca-e-motivacao.html>. Acesso em 07/10/14.

SEBRAE. Artigos para MPE'S. Disponível em: <http://www.sebrae-sc.com.br/newart/ default.asp?materia $=10410>$. Acesso em 14/08/2014.

SOUZA, Monica Maria Martins de, Editora ENIAC, Guarulhos: São Paulo, 2014. 
VOCÊ VENCEDOR. Conceito de liderança: O que é Liderança?. Disponível em: $<$ http:// www.vocevencedor.com.br/artigos/arte-de-liderar/conceito-de-lideranca-o-quee-lideranca>.Acesso em 02/11/14. 